$(n=237)$. The imputed reductions in the risk of diabetes and cardiovascular disease were $40 \%$ and $18 \%$ respectively. All components of the metabolic syndrome apart from systolic blood pressure were improved. Intervention components included information provision, group discussions, selfmonitoring of behaviour, goal-setting, and planning for behaviour change and maintenance. Full details of the intervention and its results have been reported elsewhere. ${ }^{5}$

The success of the GGT DPP in primary healthcare settings did not go unnoticed. The Department of Human Services in Victoria has already begun implementing this programme on a large scale, with the aim of having 25000 Victorians reduce their risk of type 2 diabetes by 2011 .

\section{Nathalie Davis-Lameloise}

Research Fellow, GGT UDRH, Flinders University and Deakin University, PO Box 423 Warrnambool, Victoria 3280, Australia. E-mail: Nathalie.Davis@greaterhealth.org

\section{Benjamin Philpot}

Research Associate, Flinders University and Deakin University.

\section{Prasuna Reddy}

Professor and Director of Health Services Research, Flinders University and Deakin University.

\section{James A Dunbar}

Professor and Director of Greater Green Triangle University, Flinders University and Deakin University.

\section{REFERENCES}

1. Barclay C, Procter KL, Glendenning R, et al. Can type 2 diabetes be prevented in UK general practice? A lifestyle-change feasibility study (ISAIAH). $\mathrm{Br} \mathrm{J} \mathrm{Gen}$ Pract 2008; 58(553): 541-547.

2. Tuomilehto J, Lindstrom J, Eriksson JG, et al. Prevention of type 2 diabetes mellitus by changes in lifestyle among subjects with impaired glucose tolerance. N Engl J Med 2001; 344(18): 1343-1350.

3. Lindström J, Ilanne-Parikka P, Peltonen $\mathrm{M}$, et al. Sustained reduction in the incidence of type 2 diabetes by lifestyle intervention: follow-up of the Finnish Diabetes Prevention Study. Lancet 2006; 368(9548): 1673-1679.

4. Absetz P, Valve R, Oldenburg B, et al. Type 2 diabetes prevention in the 'real world': one-year results of the GOAL Implementation Trial. Diabetes Care 2007; 30(10): 2465-2470.

5. Laatikainen T, Dunbar JA, Chapman A, et al.
Prevention of type 2 diabetes by lifestyle intervention in an Australian primary health care setting: Greater Green Triangle (GGT) Diabetes Prevention Project. BMC Public Health 2007; 7: 249

DOI: 10.3399/bjgp08X376258

\section{APMS contracts}

I read Dr Conlon's letter in your September issue ${ }^{1}$ with some incredulity and a great feeling of sympathy for those of his employees who may have been faced with redundancy or a loss of earnings in order for the practice to avoid a financial disaster. This was, after all, an APMS contract for which he made a successful bid at a price he felt was appropriate for the services he was offering. It is absolutely vital for any practice or consortium to formulate a sound business plan in advance of any APMS contract bid to see if it is economically viable. In this case, it clearly was not. Full credit must go to the PCT, of whom I am not acknowledged to be a great admirer, for increasing the payments to $85 \%$ when there was no contractual obligation for them to do so.

I hope that this example serves as an object lesson to all those practices who may be tempted to make bids for APMS contracts without doing the most basic arithmetic. It is unfortunate that more GPs today have not had the benefit of a grounding in the Classics. If they had they would understand the meaning of the Latin expression caveat emptor.

\section{Charles Zuckerman}

Northfield Health Centre, 15 St Heliers Road, Birmingham, B31 1QT.

E-mail: charles.zuckerman@blmc.co.uk

\section{REFERENCES}

1. Conlon M, Brinksman S, Manley V, et al. The NHS at 60. Br J Gen Pract 2008; 58(554): 648.

DOI: 10.3399/bjgp08X376267

\section{Authors' response}

We wanted to trigger a debate on resource inequality in health care, so were not expecting someone to call our financial judgement into question, and use our letter to warn against APMS contracts.

First, our defence: we made careful calculations, agreed and accepted by the appointing PCT. In addition, our bid price was above the minimum recommended by the BMA at the time. In that sense, we believe that responsibility for the financial judgement is a shared matter, and directing criticism at one party unhelpful.

APMS contract setting continues to evolve, and we understand that some contracts are now approaching a fairer reflection of what is needed to provide high quality care in the local context. If this continues, then APMS may yet become an effective vehicle for redressing the inequity of resource we observed in our original letter.

That said, Dr Zuckerman makes a valid point about caveat emptor. Our experience shows the real risks that a single practice faces when bidding for an APMS contract. By comparison, large commercial organisations can probably write off the loss of an underfunded contract for several years, so as to get their foot in the door.

This, however, creates a dilemma: for existing practices to sit on their hands while commercial organisations harvest large swathes of primary care, or to seek to preserve the qualities of continuity and professionalism that characterise general practice by exposing themselves to risk. Judging the effects on health inequalities of action versus inaction is difficult. The logical alternative - for large groups of independent practices to form partnerships to increase their clout - still seems too unappealing for most GPs to follow it through.

No one held a gun to our heads, but our sense of threat to general practice was and remains strong. We chose to act by applying for this contract. Despite the financial challenge, the practice team remains positive. The majority of our patients are being treated by experienced GP principals, not locums or salaried doctors on short-term contracts. Had we been over-inhibited by caveat emptor this situation could be very different. 


\author{
Maurice Conlon \\ Partner, Ridgacre Medical Centres. \\ E-mail: Maurice.Conlon@sbpct.nhs.uk
}

\section{Steve Brinksman}

Partner, Ridgacre Medical Centres.

\section{Vanessa Manley}

Partner, Ridgacre Medical Centres.

\section{Philip Saunders}

Partner, Ridgacre Medical Centres.

\section{Martyn Hull}

Partner, Ridgacre Medical Centres.

\section{Lynette Houghton \\ Director, Ridgacre Medical Centres.}

DOI: 10.3399/bjgp08X376276

\section{Rural practice}

I grow increasingly concerned for the future of small rural practices, particularly those in the Scottish islands. There is a clear probability that as the GPs presently in their single-handed posts retire, they will not be replaced and primary medical care for the island communities will be provided by resident nurses with GPs visiting the islands regularly but infrequently (once a week or, more likely, less often).

The effects of these changes will be twofold: they will save the NHS money (this is doubtless the driving influence) and they will radically alter the role of the doctor in the isles. No doubt the patients will be well and compassionately cared for by nurses, and the nurses will have at their disposal all the emergency paramedic and evacuation facilities. However, the traditional model of health care by a doctor-nurse duo, providing different and complementary skills, has been a very successful one and the standard of medical and nursing care received by islanders is exceptionally high. A nurse on her own would be hardstretched when she finds herself acting as both nurse and doctor.

Many of the isles have, in recent decades, shown a worrying trend towards falling population: below a critical number the community loses its teacher, its minister, and its doctor, and the character of the community is altered significantly. Incomers, both retired people and young families, have done much to keep the islands alive but they will be less likely to settle in the absence of a school, a kirk, and a surgery.

While it may be thought hard to justify the costs of a GP exclusively for a list of 200 patients or fewer, I think we should acknowledge the immense emotional and social support given by a resident doctor. At least let us achieve a compromise whereby a partnership of two or three GPs look after, say, four or five islands; such a partnership arrangement would allow more frequent island visits and adequate time off for the doctor. With such a scheme, the doctors would remain as day-to-day players on the stage of island life and it would certainly be much easier to attract new GPs to remote practices.

The whole future of the island GP needs an urgent review lest, by default, one island after another loses its doctor and this excellent feature of British general practice is lost for ever.

\section{John Rawlinson}

Retired GP, Cambridgeshire, Locum GP in The Hebrides and Orkney, The Malt House, Stonely, St Neots, Cambridgeshire, PE19 5EH. E-mail: jr338@hermes.cam.ac.uk

DOI: 10.3399/bjgp08X376285

\section{Cardiac rehabilitation}

I have read the editorial in the October BJGP with great interest; ${ }^{1}$ I first applied the rehabilitation process in 1945 .

Having served in three small ships I was appointed medical officer in charge of a Royal Naval convalescent home and approximately 100 beds for ratings recovering from general surgery, orthopaedic surgery, and medical cases.

Having been inspired by my previous teaching as a house surgeon, by a consultant who, influenced by the Liverpool team practiced rehabilitation and its motto 'Return to Full Function'. Thus fortified, I altered the focus of a 'convalescent home' and together with an excellent chief petty officer physiotherapist we set about rehabilitating every suitable case.

One medical case was an older chief petty officer steward, aged about 50 years, who had suffered a severe coronary thrombosis. He was bed bound and had been treated at the Royal Navy Hospital Haslar; he was sent for my care in the convalescent home in the expectation that recovery was unlikely. I waited for him to settle down and over the next week we gave him very simple hand and arm exercises. Monitoring pulse and blood pressure meantime, there were no sophisticated aids to diagnosis at that time. His response to light upper limb exercises were satisfactory, so progressive exercise over the next 6 weeks gave us hope that the damaged heart muscle had healed. The neurology was intact so he was progressively mobilised and deemed suitable for discharge home. I informed the senior medical physician at Haslar. He was amazed but agreed. It is a pity I was unable to follow him up further. I think he was honourably retired on medical grounds. I tell this story because it brings me to encourage the cult of rehabilitation and the effect it had on my future thinking; it certainly wasn't mentioned at Guys during my training there.

When I joined my practice I visited about 80 older patients, who were either bed bound or chair bound, to give them their 'pills'. This seemed a rather uneconomic way of spending my time so, in order to put some sort of 'clinical label' upon each of them, I arranged to visit them with the nearest relative I could find, examine them from top to toe, suggesting to the relatives that their elders were wasting a perfectly good life, and set about curing them. Once they were all reassured that the 'reaper was not nigh', a great change in situation took place. They got out of their beds by easy stages, out of their chairs, went outside in the fresh air, threw away most of their pills, made 